\title{
Cavopulmonary pathway modification in patients with heterotaxy and newly diagnosed or persistent pulmonary arteriovenous malformations after a modified Fontan operation
}

\author{
Doff B. McElhinney, MD, ${ }^{a}$ Gerald R. Marx, MD, ${ }^{a}$ Audrey C. Marshall, MD, ${ }^{a}$ John E. Mayer, MD, ${ }^{b}$ and
} Pedro J. del Nido, MD $^{\mathrm{b}}$

\begin{abstract}
Objective: Pulmonary arteriovenous malformations are an important but uncommon complication of cavopulmonary connection, particularly in patients with heterotaxy. Absence of hepatic venous effluent in pulmonary arterial blood seems to be a predisposing factor. Pulmonary arteriovenous malformations are most common after superior cavopulmonary anastomosis, but may develop, progress, or persist in 1 lung after Fontan completion if hepatic venous blood streams completely or primarily to the contralateral lung.
\end{abstract}

\begin{abstract}
Methods: Among 53 patients with heterotaxy and inferior vena cava interruption who underwent a modified Fontan procedure from 1985 to 2005, 8 had unilateral streaming of hepatic venous flow and clinically significant pulmonary arteriovenous malformations after hepatic venous inclusion and underwent reconfiguration of the cavopulmonary pathway. In all 8 patients, the hepatic vein-pulmonary artery pathway was contralateral to and offset from the pulmonary artery anastomosis of the single or dominant superior vena cava. Pathway reconfiguration included pulmonary arterial stenting $(\mathrm{n}=2)$, revision of the superior vena cava-pulmonary artery connection $(\mathrm{n}=1)$, construction of a branched hepatic vein-pulmonary artery conduit $(\mathrm{n}=2)$, and surgical or transcatheter construction of a direct hepatic vein-azygous vein pathway $(n=5)$.
\end{abstract}

Results: Hepatic vein-azygous vein connection led to improvement in 4 of 5 patients; other approaches typically did not lead to improvement.

Conclusions: Resolution of hypoxemia after cavopulmonary pathway reconfiguration in patients with unilateral pulmonary arteriovenous malformations and hepatic venous flow-streaming after Fontan completion supports the importance of hepatic venous effluent in the pathogenesis of pulmonary arteriovenous malformations and the practice of cavopulmonary pathway revision in such patients. Completion or reconfiguration of the Fontan circulation with direct hepatic vein-azygous vein connection may provide the most reliable mixing and bilateral distribution of hepatic venous blood in this population of patients. (J Thorac Cardiovasc Surg 2011;141:1362-70)

Supplemental material is available online.

Intrapulmonary right-to-left shunting through pulmonary arteriovenous malformations (PAVMs) is an important but uncommon consequence of cavopulmonary connection for palliation of functionally univentricular heart disease. ${ }^{1} \mathrm{~Pa}-$ tients with heterotaxy and associated interruption of the inferior vena cava (IVC) seem to be at particularly high risk for PAVMs after cavopulmonary connection. ${ }^{2-5}$ Although

From the Department of Cardiology, ${ }^{\text {a }}$ Children's Hospital and Department of Pediatrics, Harvard Medical School, Boston, Mass; and Department of Cardiac Surgery, ${ }^{b}$ Children's Hospital and Department of Surgery, Harvard Medical School, Boston, Mass.

Disclosures: Authors have nothing to disclose with regard to commercial support. Received for publication March 1, 2010; revisions received Aug 2, 2010; accepted for publication Aug 5, 2010; available ahead of print Dec 13, 2010.

Address for reprints: Doff B. McElhinney, MD, Department of Cardiology, Children's Hospital, 300 Longwood Avenue, Boston, MA 02115 (E-mail: doff.mcelhinney@ cardio.chboston.org).

0022-5223/\$36.00

Copyright $($ c 2011 by The American Association for Thoracic Surgery doi: $10.1016 /$ j.jtcvs.2010.08.088 the cause of PAVMs in patients with a bidirectional superior cavopulmonary anastomosis (bidirectional Glenn, hemi-Fontan, or Kawashima procedure; BCPA) or modified Fontan circulation (total cavopulmonary connection) is unknown, it is widely believed that absence of hepatic venous (HV) effluent in pulmonary arterial (PA) blood flow is a predisposing factor, particularly in patients with IVC interruption and the polysplenia form of heterotaxy syndrome. ${ }^{2,5,6}$ The putative agent responsible for suppressing PAVMs has not been identified, but there is increasing evidence to support the "hepatic factor" hypothesis. For example, a growing literature documents the resolution of PAVMs after restoration of HV blood flow to the affected lung(s) in patients with a cavopulmonary connection. Such situations include completion of a modified Fontan in patients with a BCPA and PAVMs, ${ }^{2,3,7-11}$ creation of a brachial arteriovenous fistula in patients with PAVMs after a unidirectional (or classic) Glenn operation, ${ }^{12}$ correction of PA discontinuity in patients with a unidirectional Fontan connection and PAVMs in the lung receiving only superior vena cava (SVC) flow, ${ }^{13}$ and cardiac transplant in patients with a BCPA or Fontan and PAVMs. ${ }^{14,15}$ 


\section{Abbreviations and Acronyms \\ $\mathrm{BCPA}=$ bidirectional superior cavopulmonary anastomosis \\ ePTFE $=$ expanded polytetrafluoroethylene \\ $\mathrm{HV}=$ hepatic vein/venous \\ IVC = inferior vena cava \\ PA = pulmonary artery/arterial \\ $\mathrm{PAVM}=$ pulmonary arteriovenous malformation \\ $\mathrm{SVC}=$ superior vena cava}

As we and others have reported, PAVMs may persist in 1 lung after inclusion of $\mathrm{HV}$ effluent in the PA circulation if the HV blood streams completely or primarily to the contralateral lung. ${ }^{2,3,16-18}$ There are also reports of PAVMs appearing after Fontan completion in the setting of HV flow-streaming, even if they were not present or clinically important after BCPA. ${ }^{5,19,20}$ The purpose of this study was to review our experience with newly diagnosed (hereafter, "new") or persistent PAVMs after a modified Fontan procedure in patients with heterotaxy, interrupted IVC, and functionally univentricular heart disease, with a focus on the impact of the anatomic construction and flow dynamics of the cavopulmonary circulation.

\section{MATERIALS AND METHODS \\ Patients}

We reviewed the records of patients with complex univentricular heart disease associated with heterotaxy and interruption of the IVC who underwent total cavopulmonary connection from 1985 to 2005 . The study was performed in accordance with a protocol approved by the Committee for Clinical Investigation at Children's Hospital Boston. Among 53 patients meeting these criteria, $8(15 \%)$ were found to have unilateral streaming of HV flow and persistence or new development of clinically significant PAVMs after completion of the Fontan circulation and are included in this study. Four other patients were known to have bilateral PAVMs after Fontan completion without evidence of HV flow streaming and are not included in this report. One of these patients had a type I portosystemic venous connection, and the other 3 patients had large and extensive PAVMs before Fontan completion that did not improve after HV inclusion. In this report, unless otherwise noted, the term "azygous vein" refers nonspecifically to the dominant azygous or hemiazygos vein that carries lower body venous return to the SVC.

All 8 study patients had interruption of the suprarenal IVC with azygous continuation to a left or right SVC. In 5 patients with bilateral SVC, the SVC receiving azygous flow was considered the "dominant" SVC. Total cavopulmonary connection (completion Fontan) was performed after bilateral BCPA in 5 patients, after unilateral BCPA in 2 patients, and without an intermediate BCPA in 1 patient with a single SVC. The median duration from BCPA to Fontan completion was 2.6 years $(0.8-8.3$ years). The modified Fontan procedure consisted of a 13to 16-mm extracardiac expanded polytetrafluoroethylene (ePTFE) conduit from the HVs to the left or right PA in 5 patients, an intracardiac lateral tunnel modified Fontan procedure in 2 patients, and a modified right atrium-to-PA connection in 1 patient (Table 1). In 3 patients, the conduit or lateral tunnel was fenestrated. In all 8 patients, the HV-PA pathway was contralateral to the single or dominant SVC-PA anastomosis, with a lateral offset (segment of PA between HV-PA and SVC-PA anastomoses) that measured at least 1 to $1.5 \mathrm{~cm}$.

\section{Pulmonary Arteriovenous Malformations}

Bilateral PAVMs after BCPA and before Fontan were diagnosed in 5 of the 8 patients. The other 3 patients, 1 of whom did not undergo intermediate BCPA, were first noted to have clinically important PAVMs after Fontan completion, based on progressive cyanosis at rest and with exercise. In the 5 patients with PAVMs after BCPA, completion of the Fontan improved arterial saturations from a median of $70 \%$ to $83 \%$, and led to resolution of PAVMs in the lung receiving HV flow. However, the PAVMs persisted in the contralateral lung. In all 3 patients with new PAVMs after Fontan, there were unilateral PAVMs contralateral to the lung receiving HV flow.

All patients had HV flow-streaming and unilateral PAVMs documented 2.2 to 9.8 years (median 5.0 years) after Fontan completion by cardiac catheterization and angiography (Figures $1-4$ ), at which time resting systemic arterial oxygen saturations ranged from $75 \%$ to $86 \%$ (median $83 \%$ ). In the patients with newly diagnosed PAVMs after Fontan completion, saturations were lower at the time of diagnosis than they were pre-Fontan. In all 3 patients with fenestrated HV-PA connections, the fenestrations had previously been closed. All patients reported pronounced exercise limitation, with exacerbation of cyanosis and dyspnea, and 3 (patients 5, 6, 7) were documented to have exacerbation of hypoxemia during submaximal exercise testing, with saturations decreasing by $7 \%$ to $14 \%$, to as low as $61 \%$ in 1 patient.

\section{Cavopulmonary Pathway Modification}

In all 8 patients, the geometry of the total cavopulmonary connection was modified in an effort to redistribute HV flow and treat the PAVMs, a median of 8.3 years (3.6-10.1 years) after the initial Fontan procedure (Table 1). A variety of strategies for HV-PA pathway modification were used, and in 3 patients, multiple modifications were performed. Before pathway modification, 3 patients underwent a brachial arteriovenous fistula, ${ }^{12}$ without improvement, and 3 patients had PAVMs embolized with coils, with minor improvement in saturations.

\section{Patient 1}

In patient 1 , who had bilateral SVCs, the hypoplastic central PA segment was stented. There was improvement in the distribution of HV blood flow after stenting, with substantial flow going to the lung previously unperfused by HV effluent. However, the PAVMs in the affected lung were severe (Figure 1), and hypoxemia persisted without substantial improvement. This patient underwent coil occlusion of large PAVMs at the same procedure as PA stenting and was listed for heart transplant 2 years later.

\section{Patient 2}

In patient 2, who had a single SVC, central PA stenting was also performed. This did not change the HV flow distribution, and there was progression of hypoxemia and PAVMs (Figure 2) leading to additional pathway modifications. This patient subsequently had a second ePTFE conduit placed between the first conduit and the lung with persistent PAVMs, in effect creating a bifurcated graft from the HV to bilateral PAs, but the second graft rapidly thrombosed. The occluded conduit was recanalized and stented in the catheterization laboratory, and the PA end of the original conduit was partially occluded with a septal occlusion device in an attempt to redistribute blood through the stented graft and to the lung with PAVMs. This patient was severely hypoxemic at the time of the procedure and died 1 month later.

\section{Patient 3}

Patient 3 also underwent placement of a second ePTFE conduit between the first conduit and the lung with persistent PAVMs to create a bifurcated 
TABLE 1. Limited summary of patient data

\begin{tabular}{|c|c|c|c|c|c|c|c|c|c|}
\hline \multirow[b]{2}{*}{$\begin{array}{c}\text { Patient } \\
\text { no. }\end{array}$} & \multirow[b]{2}{*}{$\begin{array}{c}\text { Original Fontan } \\
\text { connection }\end{array}$} & \multirow[b]{2}{*}{$\begin{array}{c}\mathrm{SPO}_{2} \text { before most } \\
\text { recent pathway } \\
\text { modification }\end{array}$} & \multicolumn{3}{|c|}{ Fontan pathway modifications } & \multirow[b]{2}{*}{$\begin{array}{c}\text { PAVM } \\
\text { coil } \\
\text { occlusion }\end{array}$} & \multirow[b]{2}{*}{$\begin{array}{c}\text { Clinical } \\
\text { improvement }\end{array}$} & \multirow[b]{2}{*}{$\begin{array}{c}\text { Follow-up } \\
\text { duration } \\
(y)\end{array}$} & \multirow[b]{2}{*}{$\begin{array}{c}\mathrm{SPO}_{2} \text { at } \\
\text { most recen } \\
\text { follow-up }\end{array}$} \\
\hline & & & $\begin{array}{c}\text { Central } \\
\text { PA } \\
\text { stent }\end{array}$ & $\begin{array}{l}\text { HV-azygous } \\
\text { vein } \\
\text { connection }\end{array}$ & $\begin{array}{c}\text { Other } \\
\text { Fontan } \\
\text { rerouting }\end{array}$ & & & & \\
\hline 1 & Left LT & 83 & $\mathrm{X}$ & & & $\mathrm{X}$ & Minimal & 2.1 & 86 \\
\hline 2 & HV-RPA ECC $16 \mathrm{~mm}$ & 80 & $\mathrm{X}$ & & Branched HV-PA conduit & $\mathrm{X}$ & No & 0.2 & Deceased \\
\hline 3 & HV-LPA ECC $14 \mathrm{~mm}$ & 84 & & $\mathrm{X}$ & Branched HV-PA conduit & & Substantial & 4.0 & 96 \\
\hline 4 & Right RA-PA & 85 & & & SVC-PA connection moved & & Modest & 13.1 & 90 \\
\hline 5 & HV-RPA ECC 16 mm & 86 & & $\mathrm{X}$ & & & Substantial & 1.0 & 97 \\
\hline 6 & HV-RPA ECC $16 \mathrm{~mm}$ & 80 & & $\mathrm{X}$ & & & Substantial & 1.8 & 91 \\
\hline 7 & Right LT & 75 & & $\mathrm{X}$ & & & Substantial & 0.2 & 87 \\
\hline 8 & LHV-LPA ECC $13 \mathrm{~mm}$ & 83 & & $\mathrm{X}$ & & $\mathrm{X}$ & No & 3.5 & Deceased \\
\hline
\end{tabular}

$\overline{E C C}$, Extracardiac conduit; $F U$, follow-up; $L P A$, left pulmonary artery; $L T$, lateral tunnel; $R P A$, right pulmonary artery; $S P O_{2}$, systemic arterial oxygen saturation by pulse oximetry.

HV-bilateral PA graft. As in patient 2, the second graft rapidly thrombosed. Attempts to recanalize the new graft in the catheterization laboratory were unsuccessful, and the graft remained occluded. This patient subsequently had a conduit placed from the HV to the azygous vein, both of which were located just about in the midline. Through a left-sided posterolateral thoracotomy without cardiopulmonary bypass, the left inferior pulmonary ligament was divided, the esophagus was mobilized, and a 12-mm ePTFE tube was sewn end-to-side to incisions in the anterior aspect of the azygous vein and the posterior aspect of the HV confluence. The original HV-PA conduit was ligated with surgical clips but not divided. As shown in Figure 5, postoperative computed tomography imaging demonstrated an unobstructed conduit. Four years after pathway revision, this patient had substantially improved symptoms and a saturation of $96 \%$ on room air, up from $84 \%$ before pathway modification.

\section{Patient 4}

In patient 4 , whose total cavopulmonary connection consisted of a rightsided atriopulmonary connection and a BCPA using the single left-sided SVC, the SVC-PA anastomosis was moved rightward. The original connection was taken down through a median sternotomy, the pulmonary arteriotomy was extended rightward, and a 19-mm ePFTE tube was used to connect the single left SVC to the PA at the level of the atriopulmonary connection. The patient was alive and well 13 years after pathway modification, with an arterial oxygen saturation of $90 \%$ (compared with $85 \%$ before revision); no catheterization had been performed since revision to assess the status of PAVMs.

\section{Patient 5}

In patient 5 , an existing abnormality of the abdominal systemic venous system was exploited to allow transcatheter conversion to an HV-azygous circuit. After BCPA, the patient was found to have a duplicated IVC system, with azygous continuation of an interrupted left IVC to a dominant left SVC, and additional connection of a right-sided suprarenal IVC to the floor of the right atrium after receiving the HVs (Figure 3). The 2 systems were in communication at the level of the renal veins with a venous segment that was posterior to the descending aorta and anterior to the vertebral column and consequently had minor compression and obstruction. The patient underwent Fontan completion with a 16-mm extracardiac conduit from the HV to the right PA. After documentation of flowstreaming and persistence of unilateral PAVMs, and evaluation of the cavopulmonary circulation during test occlusion of the HV-PA conduit, the HV-PA conduit was completely occluded with an oversized Amplatzer vascular plug II (AGA Medical, Inc, Plymouth, MN). After conduit occlusion, HV flow passed through the prevertebral connecting vein into the azygous with a $1 \mathrm{~mm} \mathrm{Hg} \mathrm{HV-azygous} \mathrm{vein} \mathrm{gradient.} \mathrm{Follow-up} \mathrm{catheter-}$ ization 4 months later demonstrated resolution of PAVMs (Figure 3), unobstructed return of $\mathrm{HV}$ blood to the azygous vein though the pre-vertebral connecting vein and to both lungs, and a systemic arterial
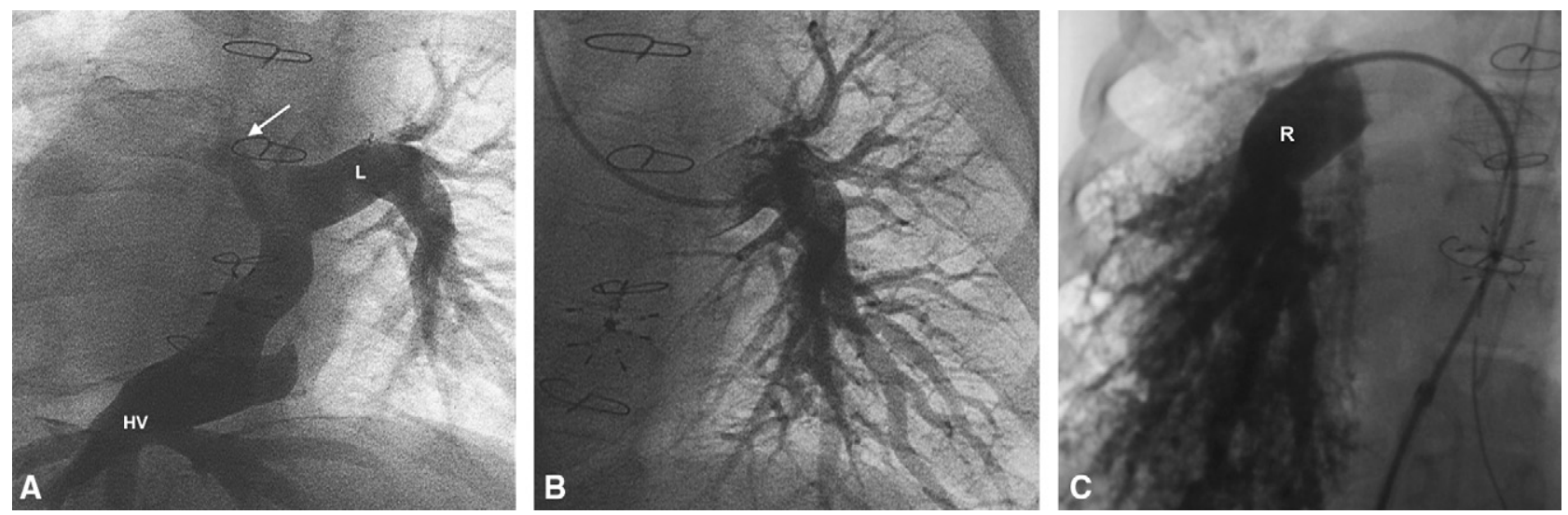

FIGURE 1. In patient 1 , the HV were baffled through a left lateral tunnel to the left PA after prior BCPA, and A) HV flow streamed to the left lung. A small amount of contrast can be seen filling but not passing across the hypoplastic central PA segment (arrow). B, There were no PAVMs in the left lung, but there were dense and advanced PAVMs throughout the right lung $(C)$. Central PA stenting facilitated HV flow to the right lung, but there was no improvement in hypoxemia. $L$, Left PA; $H V$, hepatic venous; $R$, right PA. 

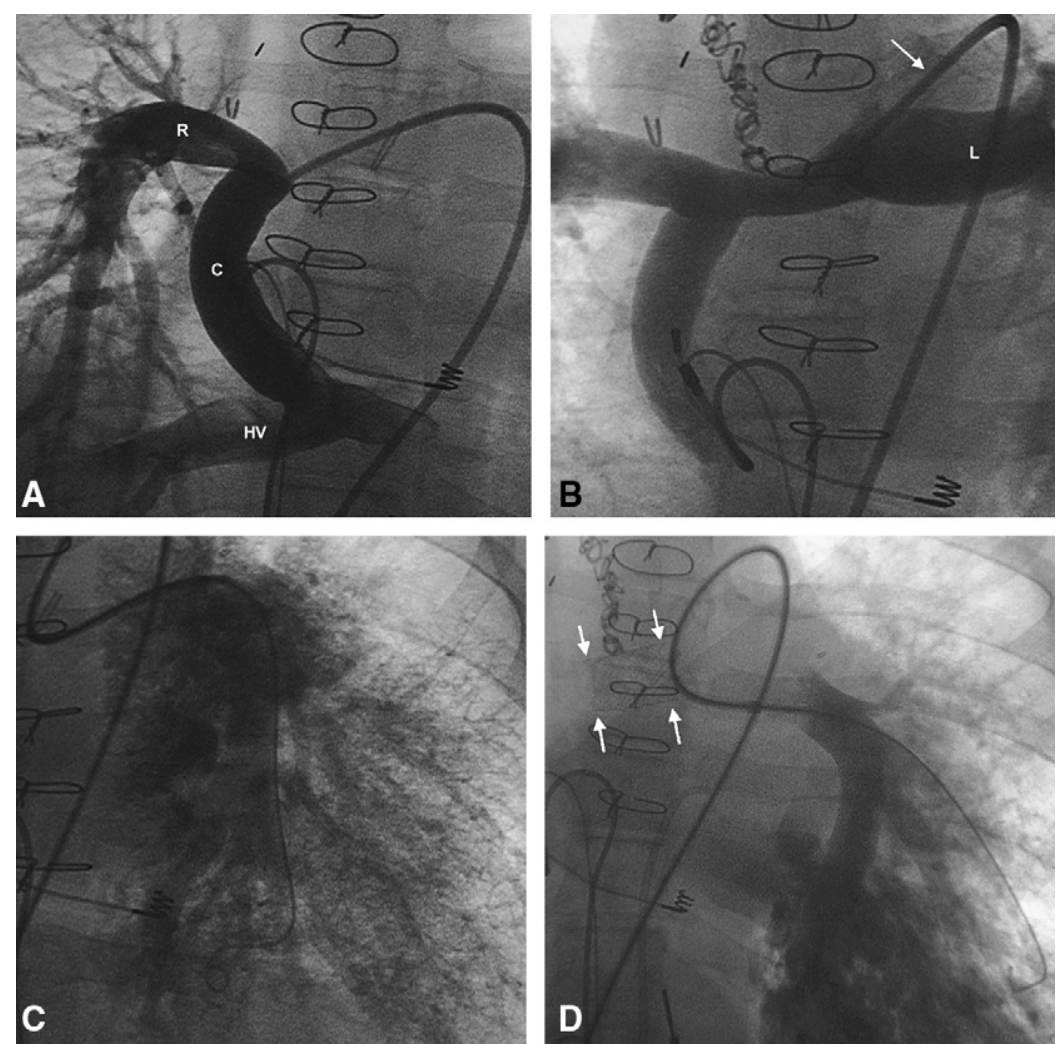

FIGURE 2. Patient 2 underwent total cavopulmonary connection without prior BCPA. A, HV flow flowed exclusively to the right lung, where there were no PAVMs. B, The azygous vein entered the left SVC (arrow indicates catheter passing from the azygous vein through the left SVC to the PAs), which was connected to the PAs leftward of the HV-PA connection. C, There were diffuse left lung PAVMs, which (D) progressed over time and after placement of a central PA stent (arrows). $C$, HV-PA conduit; $R$, right PA; $H V$, hepatic veins; $L$, left PA.

oxygen saturation of $96 \%$ on room air (compared with $86 \%$ pre-modification). At most recent follow-up, 12 months after pathway modification, systemic oxygen saturation by pulse oximetry was $97 \%$ and exercise capacity was improved.

\section{Patient 6}

In patient 6 , an $\mathrm{HV}$-azygous vein connection was performed through a right posterolateral thoracotomy without cardiopulmonary bypass. The lower portion of the right-sided HV-PA conduit was dissected free and a 16-mm ePTFE tube was used to connect this to the right-sided hemiazygos vein almost exactly at the level where the hemiazygos crossed the midline to the left azygous vein (which continued to the left SVC), with end-to-side anastomoses to both the HV and azygous vein. The original HV-PA conduit was ligated (but not divided) craniad to the new conduit using a combination of surgical clips and horizontal mattress sutures, Postoperative computed tomography demonstrated an unobstructed conduit (Figure 5). Twenty-two months after pathway modification, this patient's saturations had improved to $91 \%$ from $80 \%$, with improvement in exercise tolerance and resolution of exercise-induced cyanosis.

\section{Patient 7}

Patient 7 had a lateral tunnel connection taken down through a median sternotomy with cardiopulmonary bypass, followed by connection of the HV and azygous vein with a 14-mm ePTFE conduit. The left-sized azygous vein was exposed through an inferior posterior pericardiotomy, and the conduit was connected end-to-side to both the azygous vein and the right-sided HV confluence. At most recent follow-up, 2 months before the preparation of this article, resting saturations were up from $75 \%$ to
$87 \%$ and exercise tolerance was reportedly much improved with resolution of exercise-exacerbated cyanosis.

\section{Patient 8}

Patient 8 , in whom the right $\mathrm{HV}$ had not been incorporated into the original HV-PA connection, had a 12-mm ePTFE conduit placed from the right $\mathrm{HV}$ to the right-sided azygous vein, leaving the existing conduit from the left HV to the left PA in situ (Figure 4). This patient also underwent coil occlusion of large PAVMs. Flow from the right HV to the right PA was documented by postoperative computed tomography, but the right lung PAVMs were advanced. Hypoxemia persisted, renal failure ensued, and the patient died 3.5 years after pathway modification.

\section{DISCUSSION}

Newly Diagnosed or Persistent Unilateral Pulmonary Arteriovenous Malformations After Total Cavopulmonary Connection

We previously reported our experience with total cavopulmonary connection in patients with heterotaxy, interrupted IVC, and univentricular heart disease who had important PAVMs after a Kawashima procedure. ${ }^{2}$ In that study, we found that PAVMs typically resolved after incorporation of the HVs into the cavopulmonary circuit, but that unilateral PAVMs persisted in a minority of patients with streaming of flow from the HVs exclusively to the ipsilateral PA. Similar findings have 

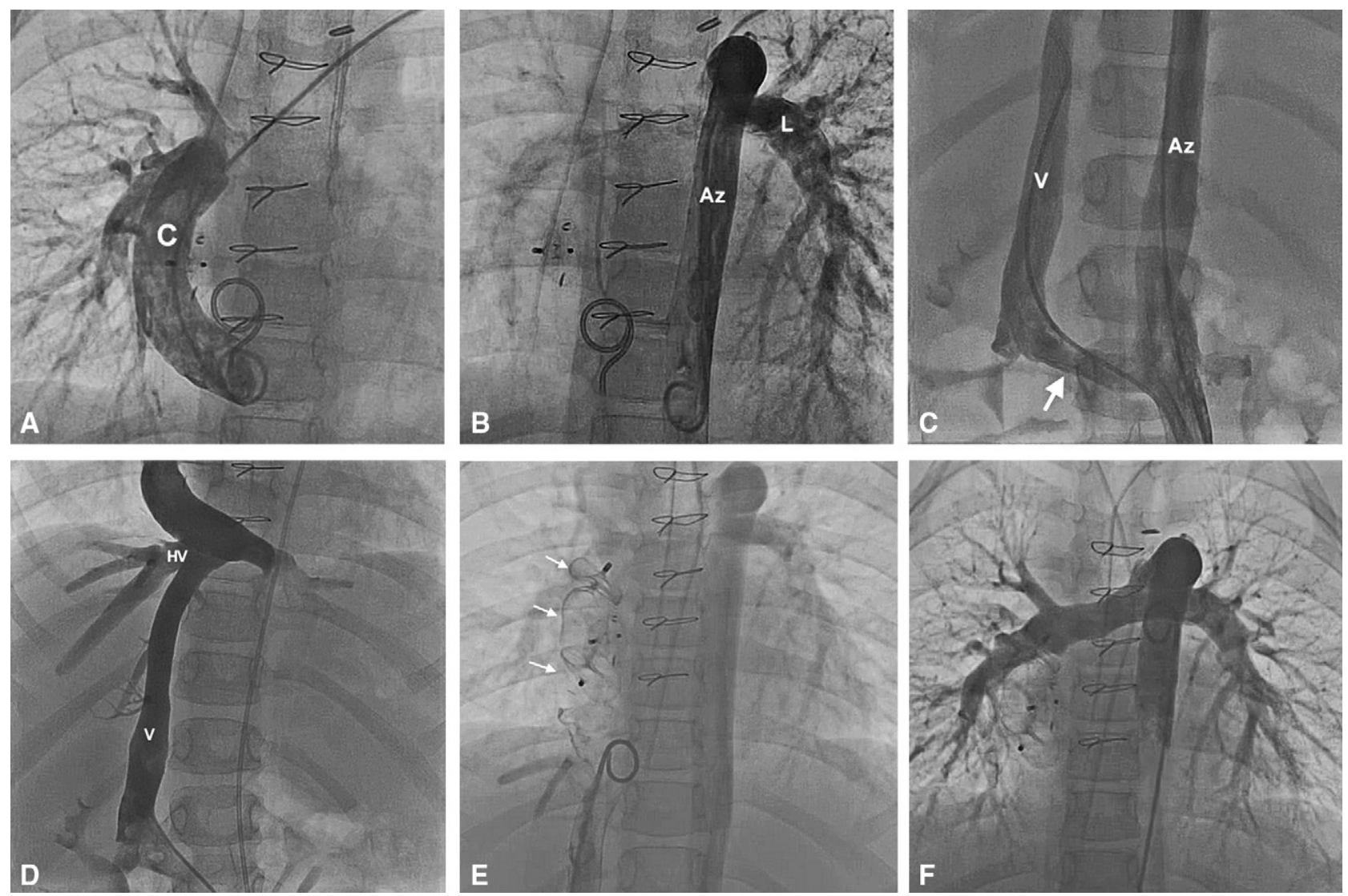

FIGURE 3. Patient 5 underwent Fontan completion by connection of the HV to the right PA with a 16-mm ePTFE conduit, which resulted in (A) streaming of HV flow exclusively to the right lung. B, The azygous vein connected to the left-sided SVC, and there were unilateral left lung PAVMs. C, D, There was also a duplicated IVC system with a connection between the HV and right-sided suprarenal IVC and between the IVC and azygous vein at the level of the renal veins (arrow). D, After completion of the modified Fontan circulation, there was no flow from the HV across this connecting vein and a small amount of flow from the azygous into the suprarenal right IVC. E, After occlusion of the HV-PA conduit with a vascular plug (arrows), HV flow passed down the suprarenal IVC, across the connecting vein into the azygous vein. F, After this reconfiguration, left lung PAVMs resolved and systemic oxygen saturation increased to $97 \%$. $C$, HV-PA conduit; $A z$, azygous vein; $L$, left PA; $V$, IVC; $H V$, hepatic veins.

been reported by others. ${ }^{3,16-18}$ As illustrated by 3 of the patients in the current series and prior reports, unilateral PAVMs may also manifest after Fontan completion as the result of flow-streaming. ${ }^{5,19,20}$ Altogether, in our experience, new or persistent PAVMs were found in $15 \%$ of patients $(8$ of 53) with this anatomy who underwent a Fontan completion, with or without intermediate BCPA. This may be an underestimate because some of the 53 patients were not followed at our center after Fontan completion.

All of the patients with flow-streaming and unilateral PAVMs in this series had separation between the PA insertions of the HV pathway and the single or dominant SVC. Kim and colleagues ${ }^{3}$ recently reported a similar pattern, and Nakamura and colleagues ${ }^{5}$ observed new PAVMs after total cavopulmonary connection in 6 of 16 patients, which were associated with HV-SVC offset and unilateral HV streaming in 5 patients. When the HVs enter the PAs laterally offset from the SVC, or from the dominant SVC in patients with bilateral SVCs, it is nearly inevitable that HV flow will distribute completely or primarily to the ipsilateral lung. $^{21,22}$ The SVC receiving azygous venous flow will carry more than $50 \%$ of systemic venous return, even in patients with bilateral SVCs, whereas the HVs tend to carry $20 \%$ to $25 \%{ }^{23}$ Thus, unless there is high resistance in the pulmonary vascular bed ipsilateral to the HV insertion, there is unlikely to be a major impetus for $\mathrm{HV}$ blood to pass to the opposite lung (Figure 6). As the offset distance between the SVC and HV connections to the PAs increases, so does the likelihood of flow-streaming. Anterior-posterior offset of the SVC-PA and HV-PA connections may also be an important consideration in establishing bilateral HV flow. ${ }^{24}$

As demonstrated in this series, reconfiguration of the cavopulmonary pathway to direct HV blood to the affected lung is often effective at improving hypoxemia due to unilateral PAVMs after total cavopulmonary connection. In 2 patients, interventions that successfully directed HV blood to the lung with persistent PAVMs did not result in resolution of PAVMs or hypoxemia. Both of these patients had very advanced and 

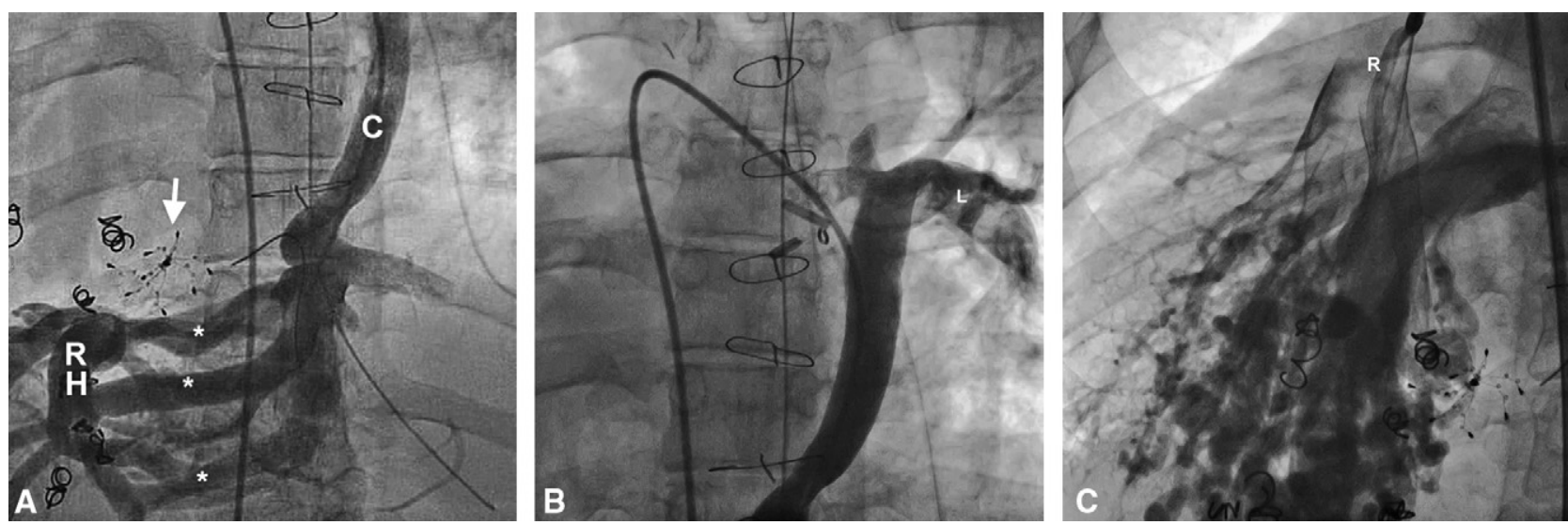

FIGURE 4. Patient 8 had a left-sided HV-PA conduit placed 6 years after bilateral BCPA. The right hepatic veins continued to drain to the atrium, and intrahepatic collaterals $(*)$ enlarged, allowing retrograde flow from the cavopulmonary circulation through HV-PA conduit, through the liver, and into the atrium. A, The HV-atrial connection was closed with an occlusion device (arrow), but (B) streaming of HV flow to the left lung continued, and (C) right lung PAVMs persisted and progressed to a dense, advanced state. Reconfiguration was performed by placing an additional ePTFE conduit from the right HV to the right PA. $R H$, Right HV; $L$, left PA; $C$, HV-PA conduit; $R$, right PA.

long-standing PAVMs (Figures 1 and 4), and it is possible that such malformations are beyond reversal. In 1 of them, the existing conduit between the left HV and PAs was left open, which may have had an adverse effect on flow through the $\mathrm{HV}$-azygous vein connection. The pathobiology of PAVM formation and resolution is poorly understood, and the hepatic factor hypothesis is based on circumstantial evidence. The failure of PAVMs to resolve after introduction of $\mathrm{HV}$ flow to the affected lung in these 2 patients highlights the limitations of our understanding of this condition.

\section{Cavopulmonary Pathway Configuration and Reconfiguration}

Given the mounting evidence that flow of HV blood to the lungs is critical to prevent PAVMs after cavopulmonary connection, particularly in patients with heterotaxy and left isomerism, one of the top priorities in completing a modified Fontan circulation in such patients should be constructing a pathway that minimizes the chances of significant streaming of HV flow toward 1 lung. This may be achieved (1) by connecting the HVs and SVC to the PAs in close enough proximity to facilitate mixing of SVC and $\mathrm{HV}$ blood and consequently bilateral $\mathrm{HV}$ flow, or (2) by directing $\mathrm{HV}$ blood into the systemic venous pathway upstream of the systemic venous insertion into the PAs. Feasible options and surgical approaches for creating such a pathway will vary according to a number of anatomic factors, including the number of SVCs; the number and location of separate HV connections to the atrium; and relationships between the HVs, SVC, azygous vein, descending aorta, ventricular mass, and pulmonary veins. In the setting of a single SVC that receives the azygous vein and is ipsilateral to the atrial entrance of the HV, a standard lateral tunnel or extracardiac conduit connection may provide a geometrically favorable connection, whereas in other circumstances, construction of an HV-PA connection that aligns with the SVC-PA anastomosis may be awkward, and an $\mathrm{HV}$-azygous vein connection may be optimal. If an HV-PA connection is used to complete the Fontan circulation in patients with bilateral SVCs, the connection should probably be juxtaposed to the SVC that receives the most flow (ie, the SVC that receives the azygous vein). When Nakamura and colleagues ${ }^{5}$ observed a high frequency of new PAVMs after total cavopulmonary connection in patients with IVC interruption, they modified their technique for lateral tunnel or extracardiac Fontan completion in this patient population, eliminating lateral HV-SVC offset. Since adopting that change, they have not encountered unilateral HV streaming or new PAVMs after a modified Fontan connection. ${ }^{5}$

In patients with unilateral PAVMs due to HV flowstreaming in an existing Fontan circulation, the question is whether and how to revise the connection to achieve adequate redistribution of $\mathrm{HV}$ blood to both lungs. In cases with a stenotic segment of PA between the HV and SVC connections to the PAs, stenting of the intervening segment may improve HV blood flow to the contralateral lung. This approach seemed to be successful in redistributing flow in 1 of our patients, but there was no resolution of hypoxemia 2 years later, presumably because of the advanced state of the PAVMs. Although stenting the central PA does not correct the offset between the HV-PA and SVC-PA connections, qualitative assessment of changes in flow can be made immediately, and assessment of the need for additional pathway modifications made accordingly. Conceptually, placing a graft from the existing HV-PA connection to the affected PA makes sense, but attempts at constructing a branched HV-PA conduit in 2 of our patients resulted in acute thrombosis of the new conduit, presumably due at least in part to stasis and competitive flow in the setting of a large effective conduit volume carrying low flow at low 


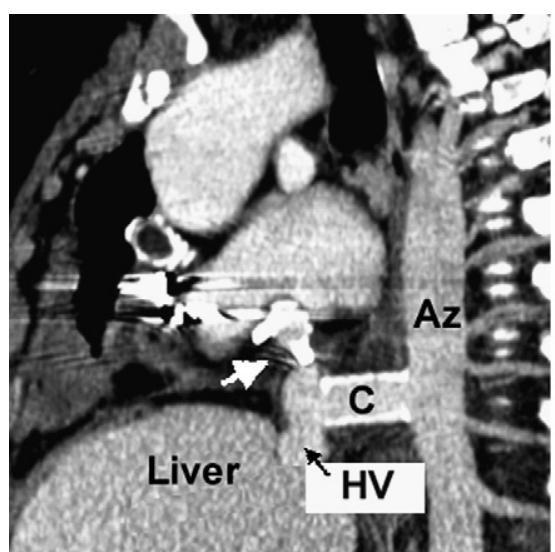

A

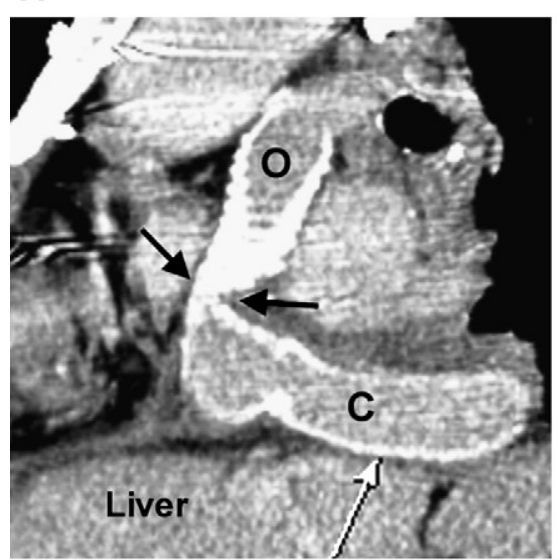

D

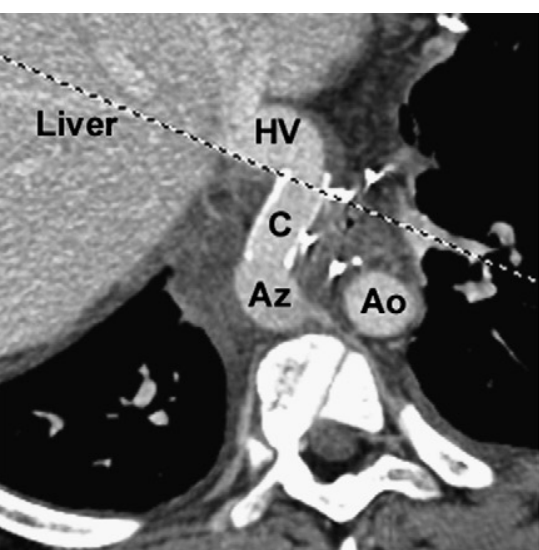

B

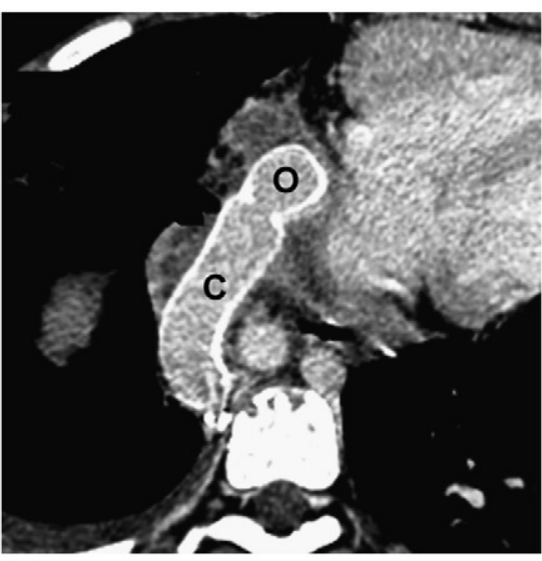

E

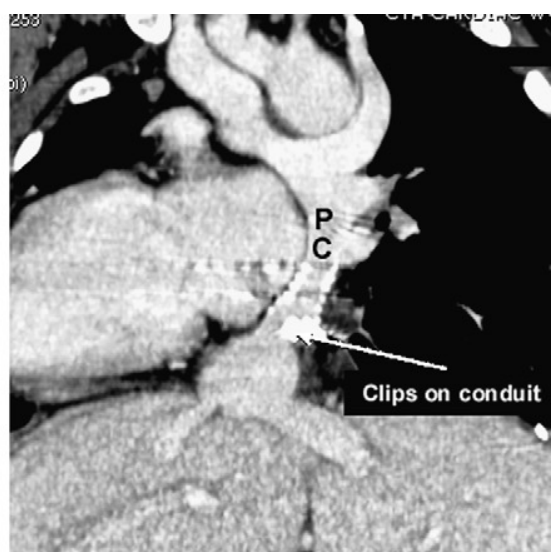

C

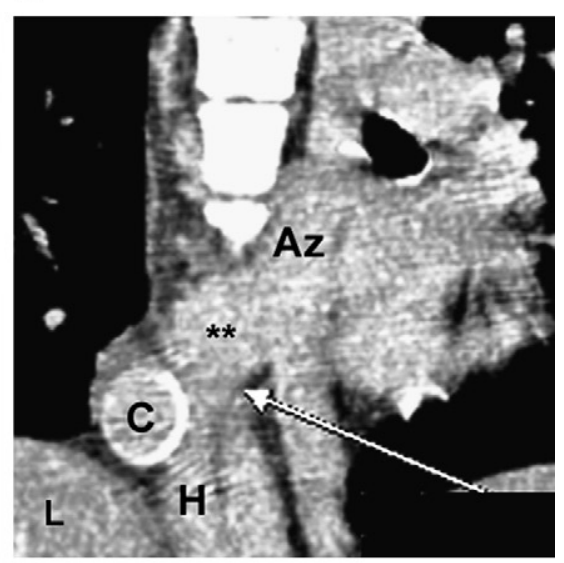

$\mathbf{F}$

FIGURE 5. Post-modification computed tomography images in patients 3 (A-C) and 6 (D-F). Images in patient 3 demonstrate the HV-azygous vein conduit (C) in parasagittal (A) and paraxial (B) planes. A, C, Arrows indicate clips that were used to ligate the inferior portion of the HV-PA conduit (PC) above the anastomosis of the HV-azygous vein conduit. The images in patient 6 demonstrate the connection between the HV-azygous vein conduit (C) and the prior HV-PA conduit (O) in parasagittal (D) and axial (E) planes. In the coronal image (F), the midline connection between right-sided hemiazygous and left-sided azygous veins is depicted with asterisks (**); the HV-azygous vein conduit can be seen near its entrance to the hemiazygous. Az, Azygous vein; $C$, HVazygous vein conduit; $H V$, hepatic veins; $A o$, descending aorta; $P C$, HV-PA conduit; $O$, HV-PA conduit; $H$, hemiazygous vein; $L$, liver.

velocity and pressure. ${ }^{25}$ We no longer consider this a suitable approach. Similarly, ligation or division of the existing HV-PA conduit may be an important element of facilitating flow through the $\mathrm{HV}$-azygous vein conduit and achieving the ultimate goal of bilateral distribution of HV blood. Creation of a brachial arteriovenous fistula (or another form of systemic-to-PA shunt) has not proven to be effective in patients with a Fontan connection of HV streaming, as discussed in a prior report. ${ }^{12}$ A strategy that is more likely to redistribute HV flow effectively is rerouting of the HV pathway either into the azygous vein, the PA at a point directly opposite the SVC anastomosis, the innominate vein, or the dominant SVC. Alternatively, the dominant SVC may be rerouted to enter the PA opposite the HV-PA connection. $\mathrm{HV}$-azygous vein connection was performed in 5 of our patients, and SVC rerouting was performed in 1 patient.

Of the various options for total cavopulmonary connection in patients with an interrupted IVC, HV-azygous vein connection may result in the most consistent venous mixing and prevention of $\mathrm{HV}$ flow-streaming, in addition to superior hydrodynamic efficiency. ${ }^{22,25}$ Compared with rerouting the $\mathrm{HV}$ to the SVC or innominate vein, or reconfiguring the prior SVC-PA anastomosis, an $\mathrm{HV}$-azygous vein connection may require less extensive dissection to mobilize the critical vessels and a shorter tube graft, which may be important considering the reported propensity for thrombosis of HV-PA conduits in these patients. ${ }^{25}$ The surgical approach and pathway for the conduit will vary according to various anatomic factors. Although it may be more complicated to modify a previously created HV-PA pathway than to create an HV-azygous vein connection as the initial Fontan connection, an existing HV-PA conduit may also be used to advantage in the rerouting, because the hepatic aspect of the conduit can be used in the reconstruction, in effect extending the size of the HV confluence and adding procedural flexibility. Several 


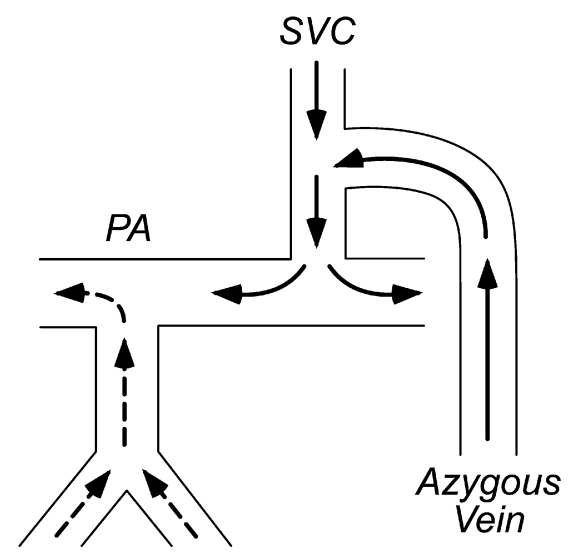

HV

A

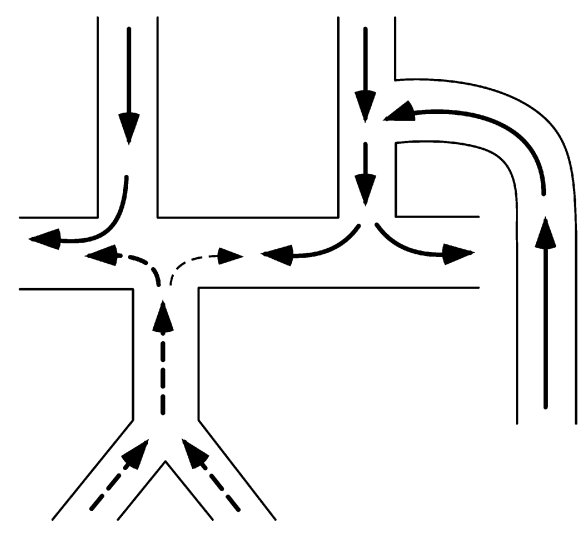

C

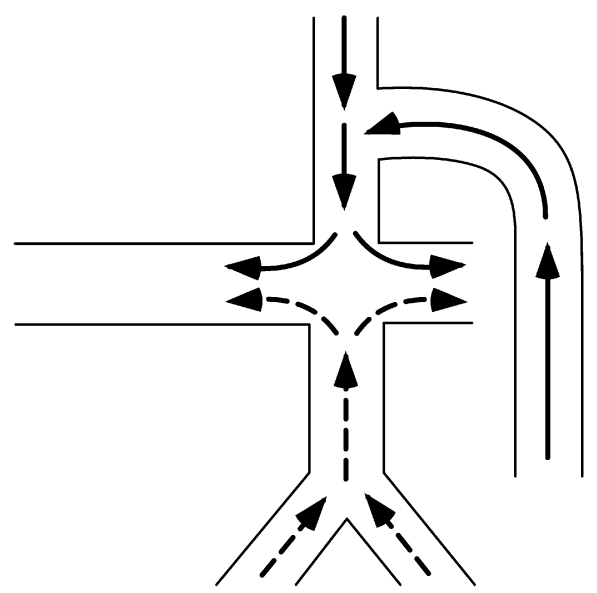

B

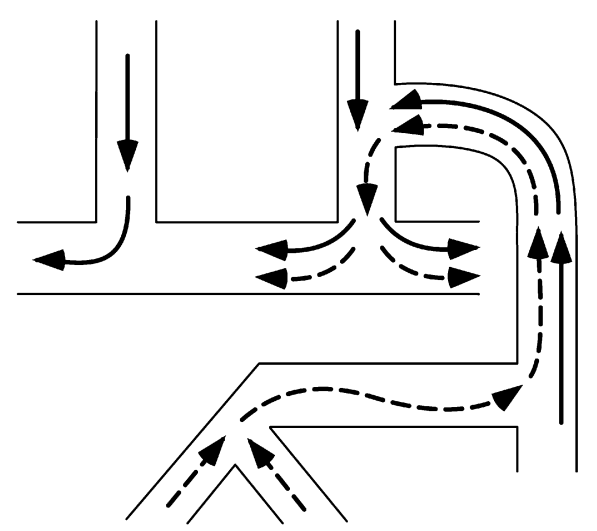

D

FIGURE 6. Schematic diagrams of HV and PA flow-streaming and interactions in several representative forms of total cavopulmonary connection in patients with IVC interruption and direct atrial drainage of the HV. Solid arrows represent the distribution of azygous and SVC return, and dashed arrows represent the distribution of $\mathrm{HV}$ return. A, There is contralateral offset of the single SVC-PA connection and the HV-PA connections, such that all HV return is to a single lung. B, The single SVC and HV connect to the PAs without lateral offset, and there is HV flow to both lungs. C, There are bilateral SVCs and connection of the HVs to the PA in proximity to the non-dominant SVC, which favors predominantly unilateral HV flow. D, With HV-azygous connection, HV blood will enter the dominant SVC, which will provide well more than half of systemic venous inflow to the PAs. Flow from the HVs will distribute in a similar fashion to azygous and SVC return, as depicted by the superimposed solid and dashed arrows. SVC, Superior vena cava; $P A$, pulmonary artery; $H V$, hepatic venous.

modifications of HV-azygous vein connection in this population have been described and depicted previously, some of which are reprinted in Figure E1., ${ }^{9,17,26-28}$ In 3 of our patients, a surgical HV-azygous connection was created through a lateral thoracotomy without cardiopulmonary bypass, which was facilitated by the presence of multiple HVs (patient 8), a large hemiazygos that crossed the midline at the level of the diaphragm (patient 6), or relatively close location of the HV and azygous vein. In another patient (patient 7), the original Fontan connection was a modified lateral tunnel, so cardiopulmonary bypass through a median sternotomy was necessary to convert that pathway to an $\mathrm{HV}$-azygous connection, and the azygous vein was exposed through a posterior pericardiotomy. Given the vari- ous anatomic and prior operative factors that may influence the pathway modification, precise preoperative definition of the potentially relevant anatomic structures is essential.

Amodeo and colleagues ${ }^{26}$ have proposed single-stage $\mathrm{HV}$-azygous vein connection along with BCPA in patients with heterotaxy, interrupted IVC, and univentricular heart disease. This approach ensures mixing and bilateral distribution of $\mathrm{HV}$ blood and avoids a period of $\mathrm{HV}$ exclusion after BCPA. Although we continue to stage most patients with an intermediate BCPA, our approach has evolved to the point that we now consider HV-azygous vein connection to be the preferred method of Fontan completion in this patient population, provided there is favorable anatomy. 


\section{CONCLUSIONS}

In patients with heterotaxy, polysplenia, an interrupted IVC, and univentricular heart disease who have undergone a Fontan procedure, new or persistent unilateral PAVMs due to HV flow-streaming are relatively common and should be considered when there is significant hypoxemia early or late after Fontan completion. Resolution of hypoxemia after cavopulmonary pathway reconfiguration in patients with heterotaxy and post-Fontan HV flow-streaming provides additional evidence in support of the hepatic factor hypothesis for the pathogenesis of PAVMs and supports the practice of revising the cavopulmonary pathway in such patients. Although various approaches may be effective for configuring and reconfiguring the cavopulmonary pathway in this patient population, direct HV-azygous vein connection may provide the most reliable and predictable mixing and bilateral distribution of $\mathrm{HV}$ blood, regardless of PA, systemic venous, and HV anatomy. It is unknown why PAVMs are more extensive in some patients or do not resolve after effective delivery of $\mathrm{HV}$ effluent, but earlier pathway rerouting in patients with established PAVMs may optimize the likelihood of resolution.

\section{References}

1. Duncan BW, Desai S. Pulmonary arteriovenous malformations after cavopulmonary anastomosis. Ann Thorac Surg. 2003;76:1759-66.

2. McElhinney DB, Kreutzer J, Lang P, Mayer JE, del Nido PJ, Lock JE. Incorporation of the hepatic veins into the cavopulmonary circulation in patients with heterotaxy and pulmonary arteriovenous malformations following a Kawashima procedure. Ann Thorac Surg. 2005;80:1597-603.

3. Kim SJ, Bae EJ, Lee JY, Lim HG, Lee C, Lee CH. Inclusion of hepatic venous drainage in patients with pulmonary arteriovenous fistulas. Ann Thorac Surg. 2009;87:548-53.

4. Brown JW, Ruzmetov M, Vijay P, Rodefeld MD, Turrentine MW. Pulmonary arteriovenous malformations in children after the Kawashima operation. Ann Thorac Surg. 2005;80:1592-6.

5. Nakamura Y, Yagihara T, Kagisaki K, Hagino I, Kobayashi J. Pulmonary arteriovenous malformations after a Fontan operation in the left isomerism and absent inferior vena cava. Eur J Cardiothorac Surg. 2009;36:69-76.

6. Srivastava D, Preminger T, Lock JE, Mandell V, Keane JF, Mayer JE Jr, et al. Hepatic venous blood in the development of pulmonary arteriovenous malformations in congenital heart disease. Circulation. 1995;92:1217-22.

7. Shah MJ, Rychik J, Fogel MA, Murphy JD, Jacobs ML. Pulmonary arteriovenous malformations after superior cavopulmonary connection: resolution after inclusion of hepatic veins in the pulmonary circulation. Ann Thorac Surg. 1997;63:960-3.

8. Kawata H, Kishimoto H, Ikawa S, Ueno T, Nakajima T, Kayatani F, et al. Pulmonary and systemic arteriovenous fistulas in patients with left isomerism. Cardiol Young. 1998;8:290-4.

9. Baskett RJ, Ross DB, Warren AE, Sharratt GP, Murphy DA. Hepatic vein to the azygous vein anastomosis for pulmonary arteriovenous fistulae. Ann Thorac Surg. 1999;68:232-3.
10. Shinohara T, Yokoyama T. Pulmonary arteriovenous malformation in patients with total cavopulmonary shunt: what role does lack of hepatic venous blood flow to the lungs play? Pediatr Cardiol. 2001;22:343-6.

11. Agnoletti G, Borghi A, Annecchino FP, Crupi G. Regression of pulmonary fistulas in congenital heart disease after redirection of hepatic venous flow to the lungs. Ann Thorac Surg. 2001;72:909-11.

12. McElhinney DB, Marshall AC, Lang P, Lock JE, Mayer JE. Creation of a brachial arteriovenous fistula for treatment of pulmonary arteriovenous malformations after cavopulmonary anastomosis. Ann Thorac Surg. 2005;80:1604-9.

13. AboulHosn J, Danon S, Levi D, Castellon Y, Child J, Moore J. Regression of pulmonary arteriovenous malformations after transcatheter reconnection of the pulmonary arteries in patients with unidirectional Fontan. Congenit Heart Dis. 2007; 2:179-84.

14. Graham K, Sondheimer H, Schaffer M. Resolution of cavopulmonary shuntassociated pulmonary arteriovenous malformation after heart transplantation. J Heart Lung Transplant. 1997;16:1271-4.

15. Lamour JM, Hsu DT, Kichuk MR, Galantowicz ME, Quaegebeur JM, Addonizio LJ. Regression of pulmonary arteriovenous malformations following heart transplantation. Pediatr Transplant. 2000;4:280-4.

16. Ichikawa H, Fukushima N, Ono M, Kita T, Matsushita T, Miyamoto Y, et al. Resolution of pulmonary arteriovenous fistula by redirection of hepatic venous blood. Ann Thorac Surg. 2004;77:1825-7.

17. Pike NA, Vricella LA, Feinstein JA, Black MD, Reitz BA. Regression of severe pulmonary arteriovenous malformations after Fontan revision and "hepatic factor" rerouting. Ann Thorac Surg. 2004;78:697-9.

18. Imoto Y, Sese A, Joh K. Redirection of the hepatic venous flow for the treatment of pulmonary arteriovenous malformations after Fontan operation. Pediatr Cardiol. 2006;27:490-2.

19. Justino H, Benson LN, Freedom RM. Development of unilateral pulmonary arteriovenous malformations due to unequal distribution of hepatic venous flow. Circulation. 2001;103:E39-40.

20. Wu IH, Nguyen KH. Redirection of hepatic drainage for treatment of pulmonary arteriovenous malformations following the Fontan procedure. Pediatr Cardiol. 2006;27:519-22.

21. Walker PG, Howe TT, Davies RL, Fisher J, Watterson KG. Distribution of hepatic venous blood in the total cavo-pulmonary connection: an in vitro study. Eur J Cardiothorac Surg. 2000;17:658-65.

22. Kim SH, Park YH, Cho BK. Hemodynamics of the total cavopulmonary connection: an in vitro study. Yonsei Med J. 1997;38:33-9.

23. Brundin T, Wahren J. Whole body and splanchnic oxygen consumption and blood flow after oral ingestion of fructose or glucose. Am J Physiol. 1993;264: E504-13.

24. Bove EL, de Leval MR, Migliavacca F, Guadagni G, Dubini G. Computational fluid dynamics in the evaluation of hemodynamic performance of cavopulmonary connections after the Norwood procedure for hypoplastic left heart syndrome. J Thorac Cardiovasc Surg. 2003;126:1040-7.

25. Konstantinov IE, Puga FJ, Alexi-Meskishvili VV. Thrombosis of intracardiac or extracardiac conduits after modified Fontan operation in patients with azygous continuation of the inferior vena cava. Ann Thorac Surg. 2001;72:1641-4.

26. Amodeo A, Grigioni M, Filippelli S, Gagliardi MG, Del Gaudio C, Morbiducci U, et al. Improved management of systemic venous anomalies in a single ventricle: new rationale. J Thorac Cardiovasc Surg. 2009;138: 1154-9.

27. Kaneko Y, Murakami A, Miyamoto T, Takamoto S. Hepatic vein-to-azygos vein connection in a patient with interrupted inferior vena cava. Eur J Cardiothorac Surg. 2002;21:582-4.

28. Steinberg J, Alfieris GM, Brandt B 3rd, Smith F, Byrum CJ, Fink GW, et al. New approach to the surgical management of pulmonary arteriovenous malformations after cavopulmonary anastomosis. Ann Thorac Surg. 2003;75:1640-2. 

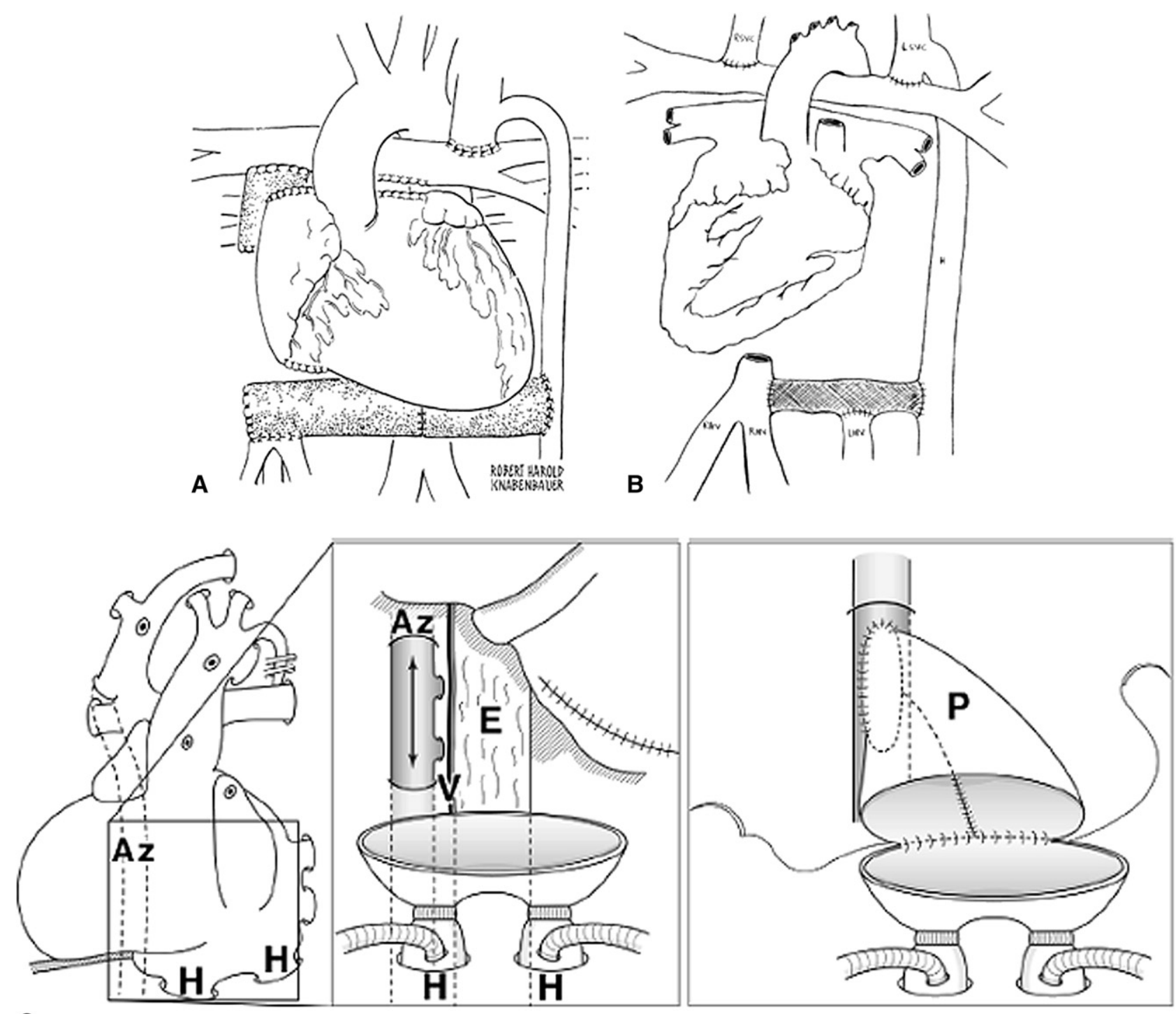

C

FIGURE E1. Pike and colleagues ${ }^{17}$ (A) and Steinberg and colleagues ${ }^{28}$ (B) depicted placement of a conduit from the right-sided HV to a contralateral

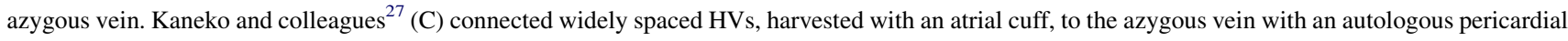
roll. $A z$, Azygous vein; $H$, hepatic veins; $V$, vagus nerve; $E$, esophagus; and $P$, pericardial roll. 